\title{
Correction to: Prevention of coronary obstruction in patients at risk undergoing transcatheter aortic valve implantation: the Hamburg BASILICA experience
}

\author{
Dirk Westermann ${ }^{1,2} \cdot$ Sebastian Ludwig ${ }^{1,2}$ - Daniel Kalbacher ${ }^{1,2} \cdot$ Clemens Spink $^{3} \cdot$ Matthias Linder $^{1}$. \\ Oliver D. Bhadra ${ }^{4}$. Julius Nikorowitsch ${ }^{1}$ - Lara Waldschmidt ${ }^{1}$ - Till Demal ${ }^{4} \cdot$ Lisa Voigtländer $^{1,2}$. Andreas Schaefer ${ }^{4}$. \\ Moritz Seiffert ${ }^{1,2}$. Simon Pecha ${ }^{2,4}$. Niklas Schofer ${ }^{1}$ - Adam B. Greenbaum ${ }^{5} \cdot$ Hermann Reichenspurnerer, . $^{2}$ \\ Stefan Blankenberg ${ }^{1,2} \cdot$ Lenard Conradi $^{2,4} \cdot$ Johannes Schirmer ${ }^{4}$
}

Published online: 4 August 2021

(c) The Author(s) 2021

\section{Correction to: Clinical Research in Cardiology https://doi.org/10.1007/s00392-021-01881-4}

The original version of this article, published on June 22, 2021, contained a mistake. The affiliations were assigned incorrectly. The correct information is given above. The original article has been corrected.

Open Access This article is licensed under a Creative Commons Attribution 4.0 International License, which permits use, sharing, adaptation, distribution and reproduction in any medium or format, as long as you give appropriate credit to the original author(s) and the source, provide a link to the Creative Commons licence, and indicate if changes were made. The images or other third party material in this article are included in the article's Creative Commons licence, unless indicated otherwise in a credit line to the material. If material is not included in the article's Creative Commons licence and your intended use is not permitted by statutory regulation or exceeds the permitted use, you will need to obtain permission directly from the copyright holder. To view a copy of this licence, visit http://creativecommons.org/licenses/by/4.0/.

The original article can be found online at https://doi.org/10.1007/ s00392-021-01881-4.

Sebastian Ludwig

se.ludwig@uke.de

1 Department of Cardiology, University Heart and Vascular Center Hamburg, University Medical Center HamburgEppendorf, Martinistrasse 52, 20246 Hamburg, Germany

2 German Center for Cardiovascular Research (DZHK), Partner Site Hamburg/Luebeck/Kiel, Hamburg, Germany

3 Department of Diagnostic and Interventional Radiology and Nuclear Medicine, University Medical Center Hamburg-Eppendorf, Hamburg, Germany

4 Department of Cardiovascular Surgery, University Heart and Vascular Center Hamburg, Hamburg, Germany

5 Structural Heart and Valve Center, Emory University Hospital, Atlanta, GA, USA 